\title{
ESTUDO EDAFOLÓGICO DAS ALGAROBAS UTILIZANDO A ESPECTROSCOPIA DE REFLECTÂNCIA NO MUNICÍPIO DE CURAÇÁ-BA
}

\author{
SANTOS, Jonathas J. ${ }^{1}$; CHAVES, Joselisa M. ${ }^{2}$; SOUZA, Deorgia T. M. ${ }^{3}$ e FRANCA- \\ ROCHA, Washington, J. S. ${ }^{4}$ \\ 1. Bolsista PIBIC/FAPESB, Graduando em Bacharelado em Geografia, Universidade Estadual de Feira de Santana, e-mail: \\ jonathas020@hotmail.com \\ 2. Orientadora, Departamento de Ciências Exatas, Universidade Estadual de Feira de Santana, e-mail: joselisa@uefs.br \\ 3. Co-orientadora, Departamento de Ciências Humanas e Filosofia, Universidade Estadual de Feira de Santana, e-mail: \\ deorgiasouza@yahoo.com.br \\ 4. Co-orientador, Departamento de Ciências Exatas, Universidade Estadual de Feira de Santana, e-mail: wrocha@uefs.br
}

PALAVRAS-CHAVE: Espectrorradiometria; solos; vegetação.

\section{INTRODUÇÃO}

A relação solo-planta pode ser estudada através da Edafologia, que de acordo com Sengik (2003), é o estudo do solo pondo-se em vista os vegetais superiores. Nesse sentido, o estudo edafológico é de suma importância para a compreensão da influência do solo para as plantas. De acordo com Florenzano (2008), o Sensoriamento Remoto é a tecnologia que permite obter imagens e outros tipos de dados da superfície terrestre. Nesse contexto, a espectroscopia desempenha um papel fundamental uma vez que permite analisar a assinatura espectral do objeto pesquisado, no caso deste trabalho, a assinatura espectral da Algaroba e dos solos no qual estão subjacente a esta espécie, permitindo analisar posteriormente a absorção espectral de seus constituintes. A Algaroba [Prosopis juliflora (SW)DC], de acordo com Andrade (2010), é uma espécie vegetal invasora originada do Peru que foi introduzida no semiárido nordestino com o objetivo de resolver problemas socioeconômicos no sertão e que na atualidade concentrase na maioria das vezes em planícies fluviais, acompanhando os cursos de água. Entretanto, a invasão biológica é um dos principais fatores de perda de biodiversidade. De acordo com Sampaio (2006), a mineralogia do solo constitui-se um fator fundamental para a compreensão de suas características no que diz respeito a sua gênese, comportamento químico e físico e um indicativo de nutrientes para a vegetação. O objetivo geral desse trabalho consiste na identificação do comportamento espectral dos solos com presença e não presença da espécie invasora Algaroba, na região norte da Bahia, utilizando a espectroscopia de reflectância. Os objetivos específicos são identificar áreas com predominância das Algarobas por imagem de satélite, utilizando como princípio uma escala temporal. Comparar as características mineralógicas dos solos com e sem presença de Algaroba. Caracterizar mineralogicamente os solos com presença e não presença da espécie de Algaroba, a partir do espectrorradiômetro e identificar os solos que estão presentes na área da cobertura vegetal da espécie Algaroba.

\section{MATERIAL E MÉTODOS}

Para que este trabalho fosse realizado, durante toda a pesquisa foi elaborado um referencial teórico sobre Edafologia, Algaroba, solos, minerais e Sensoriamento Remoto. Realizou-se um planejamento de campo para o município de Curaçá-BA, identificando por imagens de alta resolução de satélite os locais favoráveis para a criação dos pontos. Os critérios utilizados para a escolha desses locais consistiram na observação das feições da vegetação. Posteriormente, 
foram feitos com o uso de geotecnologias mapas de solo, declividade, uso e ocupação da terra, hidrografia, litologia, NDVI e rodovias do município de Curaçá-BA, com todos os pontos plotados no mapa para que fosse realizada uma análise integrada da paisagem. O Field Spec® 4 é um aparelho portátil de espectorradiometria que permitiu a obtenção de dados de refletância dos solos, vegetação, água e a identificação dos minerais. O instrumento Field Spec® foi aplicado para caracterização espectral das folhas da Algaroba, Caatinga de Porco e identificação dos argilominerais presentes nas amostras de solos coletadas em ambiente com presença de Algaroba e áreas preservadas da Caatinga. Os dados da pesquisa foram obtidos mediante o trabalho de campo (Figura 2). O comportamento espectral da Algaroba e de outra espécie vegetal conhecida como "Caatinga de porco" ou Caatingueira foram medidas em campo, já estas foram espécies encontradas nas proximidades das Algarabas. As amostras de solo foram colhidas utilizando o instrumento trado, com a perfuração á $20 \mathrm{~cm}$ de profundidade. As amostras de solo foram levadas para análise de seu comportamento espectral no Laboratório de espectrorradiometria Labespectro da UEFS. Nesse contexto, as amostras de solo foram distorradas, peneiradas em malha de $2 \mathrm{~mm}$ e secadas na estufa a $45^{\circ}$ por 24 horas, de acordo com a metodologia de BEN-DOR(2002) . Posteriormente, foi realizada a mediação do comportamento espectral de cada amostra de solo dos diferentes pontos do trabalho de campo.

\section{RESULTADOS E DISCUSSÃO}

Com o trabalho de campo realizado no município de Curaçá-BA foram colhidas amostras de diferentes áreas do município (Figura 1). Foram feitas várias análises do comportamento espectral da folha da Algaroba em campo (Figura 2), bem como verificou-se uma outra espécie vegetal com características bem próxima a Algaroba, analisando-se também o seu comportamento espectral (Figura 3), uma espécie conhecida como Caatinga de porco, ou caatingueira [Caesalpinia pyramidalis Tul], espécie endêmica da caatinga que também acompanha cursos e drenagens fluviais, podendo confundir-se com a Algaroba em imagens de satélite.
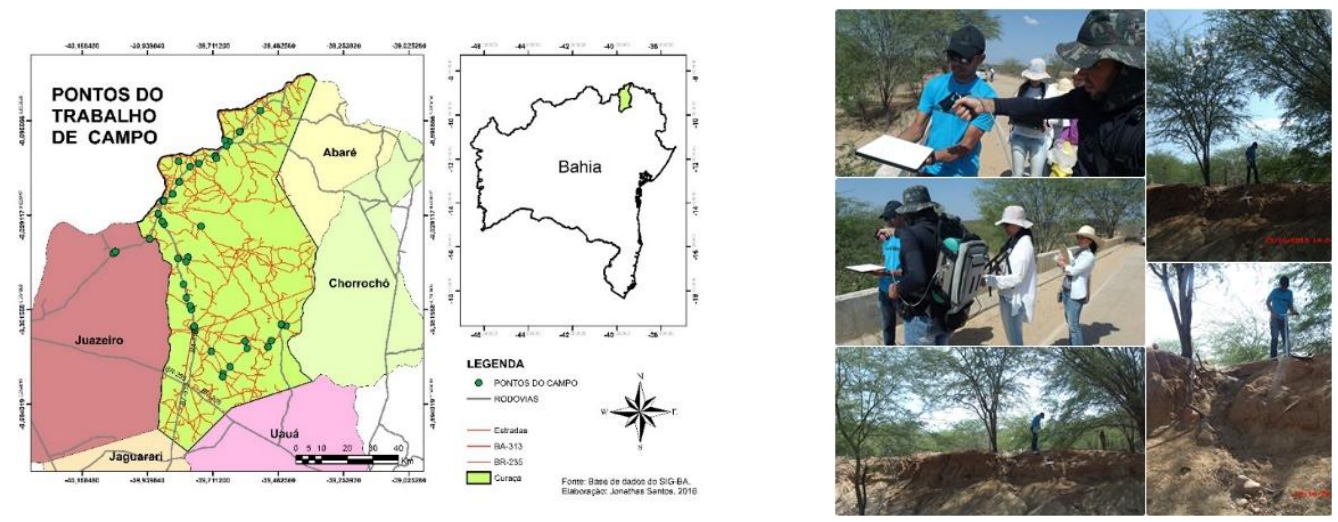

Figura 1: Espacialização dos pontos no município de Figura 2: Medição do comportamento espectral e coleta Curaçá-BA de solos em campo. FOTO: ROCHA, 2015.

A avaliação do comportamento espectral dos solos com e sem Algaroba demonstraram que existe pouca variação de minerais (Figuras 5 e 6), demonstrando que a Algaroba é muito adaptada as condições locais dos solos do semiárido. Os principais minerais encontrados foram basicamente a Montmorilonita que faz parte da absorção dos minerais 2:1, (Mg,Ca)O. $\mathrm{Al}_{2} \mathrm{O}_{3} \mathrm{Si}_{5} \mathrm{O}_{10} \cdot \mathrm{nH}_{2} \mathrm{O}$, Caulinita $\mathrm{Al}_{2} \mathrm{Si}_{2} \mathrm{O}_{5}(\mathrm{OH})_{4}$ e Goethita $\mathrm{Fe}^{3+} \mathrm{O}(\mathrm{OH})$. De acordo com 
Mendes (2007) "cerca de $90 \%$ da matéria seca de uma planta consiste de C, H e O. De maneira geral no estudo da fertilidade do solo esses três elementos não são considerados, uma vez que o solo não é a maior fonte destes".

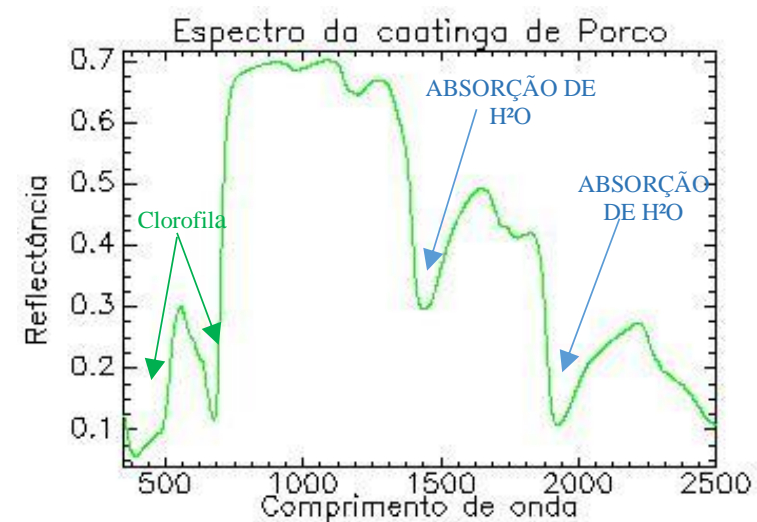

Figura 3: Análise do comportamento espectral vegetal Caatinga de Porco

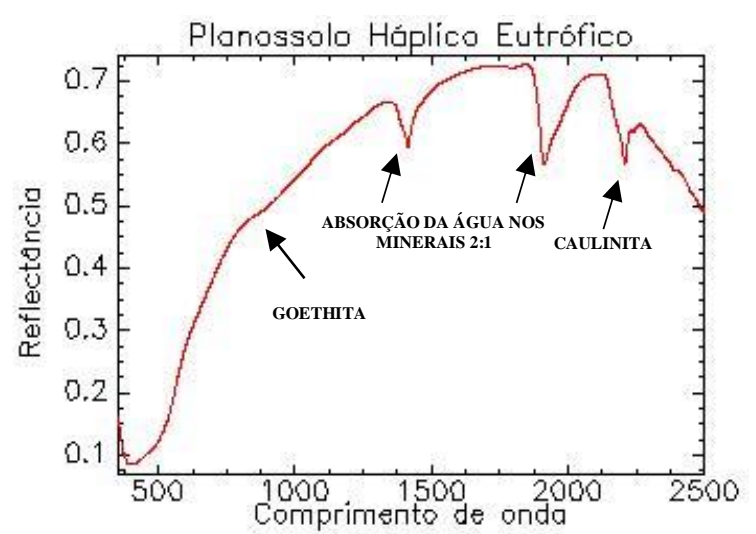

Figura 5: Comportamento espectral do solo com Algaroba

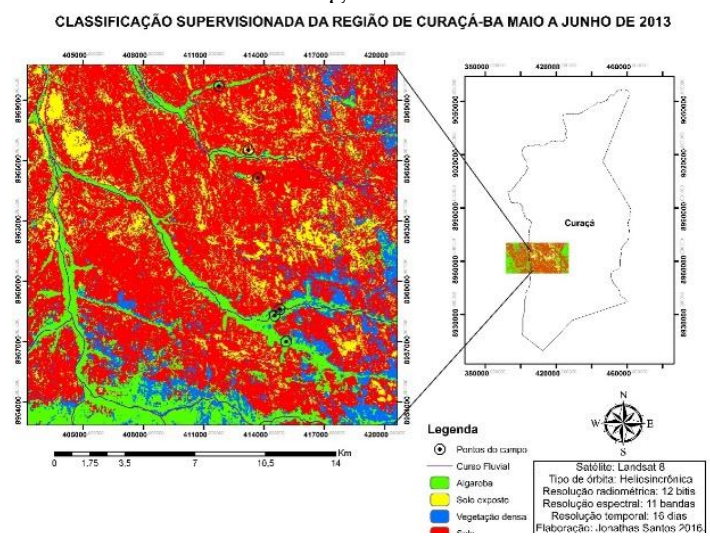

Figura 7: Identificação da proliferação da Algaroba ano de 2013 em Curaçá-BA

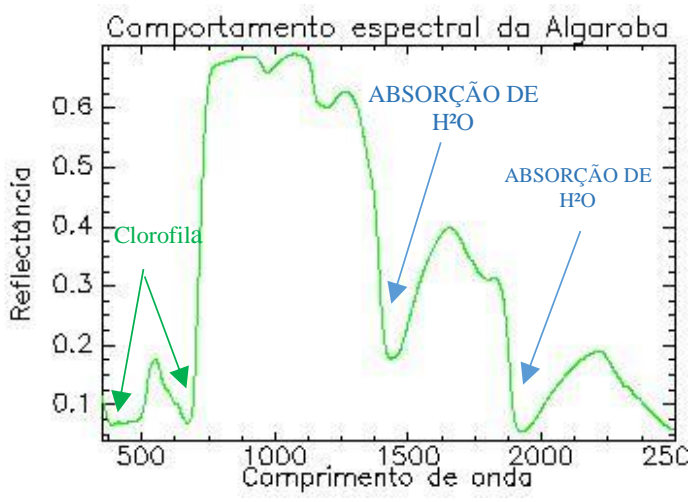

Figura 4: Análise do comportamento espectral vegetal Algaroba

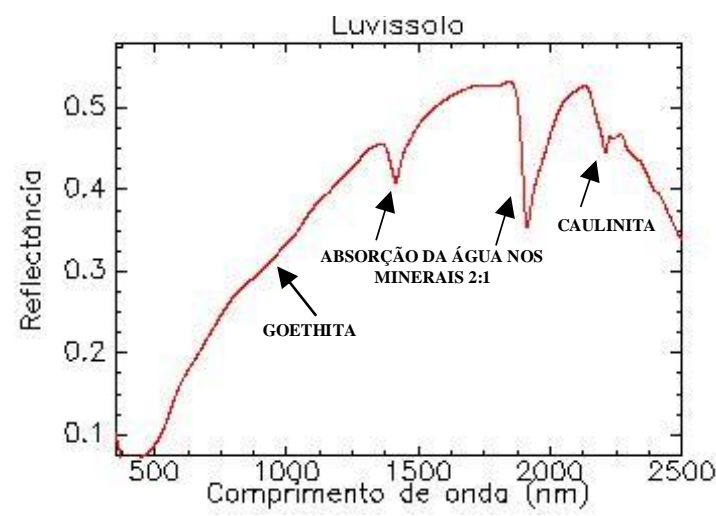

Figura 6: Comportamento espectral do solo sem Algaroba

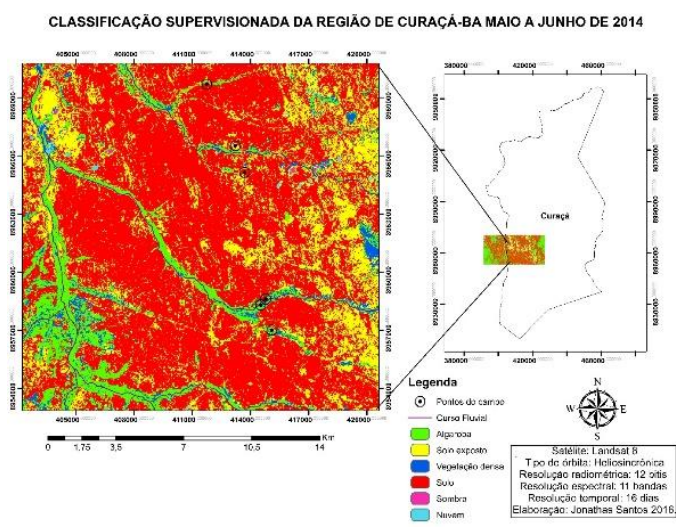

Figura 8: Identificação da proliferação da Algaroba ano de 2014 em Curaçá-BA

Com a classificação supervisionada de imagens de satélite observa-se diferenças na distribuição da cobertura vegetal da região de Curaçá-BA ano 2013 e 2014 (Figura 7 e 8). Observa-se 
claramente na classificação supervisionada de 2014, uma redução da cobertura vegetal densa, em comparação ao ano anterior 2013.

\section{CONCLUSÃO}

O presente trabalho possibilitou o estudo edafológico das Algarobras utilizando técnicas de espectrorradiometria de reflectância no município de Curaçá - BA. Nesse contexto, foram analisados através da espectrorradiometria solo e vegetação, permitindo uma análise da relação solo-planta com a identificação dos minerais presentes nos solos com e sem Algaroba. Também foram utilizadas imagens de satélite para identificação de áreas com a proliferação da espécie vegetal Algaroba e o seu comportamento natural entre os anos de 2013 e 2014. Logo, o trabalho foi significativo para melhor compreender esta espécie vegetal invasora no semiárido. Verificase que a Algaroba pode facilmente ser confundida por imagens de satélite com outra espécie vegetal conhecida popularmente como Caatinga de Porco ou Caatingueira que de igual forma com a Algaroba prolifera-se em planícies aluviais acompanhando os cursos de água, competindo com a Algaroba por espaço natural. Em contrapartida, a Caatinga de Porco apresentou nas análises espectrais uma maior reflectância da clorofila mesmo em áreas de pouca umidade com menor absorção de água em comparação com a Algaroba, demonstrando que a Caatinga de Porco é muito mais adaptada as condições locais, tratando-se de uma espécie vegetal endêmica da caatinga em contraposição à Algaroba que é uma espécie invasora que foi inserida no semiárido através da ação antrópica. Já os solos analisados com presença e sem presença da Algaroba da região de Curaçá-BA demonstraram que existe pouca variação de minerais nos solos com Algaroba e nos solos sem Algaroba, demonstrando que essa espécie vegetal tem facilidade de prolifera-se nos solos do semiárido, principalmente nos solos de planícies fluviais com maior disponibilidade de água. Com a identificação dos minerais, podese ter uma dimensão dos macronutrientes presentes nos solos com Algaroba, como a presença do $\mathrm{Mg}$ e Ca que compõem quimicamente a Montmorilonita são macronutrientes e do Fe que se trata de um micronutriente. Observa-se na análise temporal uma redução significativa da vegetação densa e a prevalência da Algaroba em planícies fluviais acompanhado os cursos de água. Essa espécie vegetal se prolifera facilmente no semiárido estando adaptada aos mais variados tipos de solos do sertão, se aproveitando dos seus nutrientes e da disponibilidade de água. Entretanto, observa-se que a invasão biológica é um dos principais fatores de perda de biodiversidade e que a Algaroba pode representar um risco para outras espécies vegetais do semiárido.

\section{REFERÊNCIAS}

ANDRADE, L.A. Impactos da invasão de Prosopisjuliflora (sw.) DC. (Fabaceae) sobre o estrato arbustivo-arbóreo em áreas de Caatinga no Estado da Paraíba, Brasil. Maringá: Acta Scientiarum Biological Sciences, 2010.

FLORENZANO, T. G. (org.). Geomorfologia: conceitos e tecnologias atuais. São Paulo: Oficina de Textos, 2008.

MENDES, A. M. S. Curso de Manejo e Conservação do solo e da Água promovido pela superintendência Federal da Agricultura, Pecuária e Abastecimento do Estado da Bahia - SFA-BA. Barreiras-BA: UFBA, 2007.

SAMPAIO, E. Mineralogia do solo. Portugal: Universidade de Évora, 2006.

SENGIK, É. S. Uma visão global de solos. Maringá: NUPEL-UEM, 2003. 